\title{
Protective effects of pineapple (Ananas comosus) on liver and kidney of Wistar rats intoxicated with Doliprane ${ }^{\circledR}$
}

\author{
T. J. DOUGNON ${ }^{1 *}$, T. M. KPODEKON ${ }^{1}$ and A. LALEYE ${ }^{2}$ \\ ${ }^{1}$ Laboratoire de Recherches en Biologie Appliquée (LARBA), University of Abomey-Calavi (UAC), \\ 01 BP 2009 Cotonou, Bénin. \\ ${ }^{2}$ Unité de Biologie Humaine, Faculté des Sciences de la Santé, UAC, Cotonou, Bénin. \\ "Corresponding author, Email: dougnonj@yahoo.fr
}

\begin{abstract}
Effect of pineapple (Ananas comosus) on liver and kidney detoxication was studied in Wistar rats. Rats were treated with paracetamol at the dose of $2 \mathrm{~g} / \mathrm{kg}$ of body weight per day for 6 weeks and then by Ananas comosus' extract (0.06- $0.12 \mathrm{ml} / \mathrm{kg}$ body weight). Administration of paracetamol induced hepatomegaly with a centrolobular necrosis and an increase in kidney weight. Treatment with Ananas comosus' extract induced a reduction of hepatic lesions but no effect on kidney. These data suggest that Ananas comosus extract treatment reduces hepatotoxicity of paracetamol in Wistar rats.

(C) 2009 International Formulae Group. All rights reserved.
\end{abstract}

Keywords: Ananas comosus, Wistar rats, paracetamol, liver, kidney, detoxication.

\section{INTRODUCTION}

The liver plays an important role in metabolism, degradation of most substances after oxidation, reduction, combination or methylation (McGeown, 2003). The etiology of fulminant hepatitis varies in different countries and at different times. A viral etiology (in particular hepatitis B virus) is now less frequent and paracetamol-induced fulminant hepatic failure is more common in the world (Ichai and Samuel, 2008). The occurrence of hepatotoxicity has been closely associated with the formation of chemically reactive metabolites (Antoine et al., 2008).

The annual incidence of these diseases is worrying. Their frequency is far greater than that assessed on pharmacovigilance data basis (Lenoir et al., 2003). At present, the number of effective and safe drugs for treatment of $\mathrm{HBV}$ and $\mathrm{HCV}$ is still limited (Liu, 2009). Alterations of the liver have become a real problem, especially in several regions of Africa for an endogenous therapy (Sofowora, 1996).
The aim of this study is to evaluate Ananas comosus protective effects on the liver and kidneys in Wistar rats, intoxicated with paracetamol.

\section{MATERIALS AND METHODS \\ Animals}

The study was conducted on 120 three-months-old Wistar male rats of average weight of $130 \mathrm{~g}$ obtained from the animal house of Human Biology Unit, Medicine School, University of Abomey-Calavi, Benin. Animals were divided into four groups of 30 rats each. They were housed in standard wire mesh cages with stainless steel tray floor, in a room with temperature maintained at $22{ }^{\circ} \mathrm{C}$, relative humidity averaging $90 \%$ and a photoperiod of 12 hours per day. Diet and drinking water were provided ad libitum.

\section{Ananas comosus}

Ananas comosus, used to obtain the extract was cropped from the Atlantic Department located in the South of Benin. Its specimen was identified, certificated and 
conserved in the National Herbarium of Benin ( ${ }^{\circ}$ AA 6336/HNB).

\section{Preparation of paracetamol (Doliprane $\left.{ }^{\circledR}\right)$ for induction of liver and kidney toxicity and Ananas comosus' extract}

The fresh pineapple was transformed to obtain the extract using the technique described by Park et al. (2001).

During the experiments, the median lethal dose $\left(\mathrm{LD}_{50}\right)$ of paracetamol for Wistar rats was determined ( $4 \mathrm{~g} / \mathrm{kg}$ body weight) using the method described by Lorke (1983). $2 \mathrm{~g} / \mathrm{kg}$ body weight/day of Doliprane ${ }^{\circledR}$ has been chosen as induction dose of liver toxicity in the rats. This dose was dissolved in $2 \mathrm{ml}$ water and administered individually per os to the Wistar rats for 6 weeks. The Doliprane ${ }^{\circledR}$ used for liver toxicity and kidney contains $20 \%$ of paracetamol.

\section{The animal groups}

Lot $n^{\circ} 1$ (30 rats): animals receiving neither Doliprane ${ }^{\circledR}$, nor extract of Ananas comosus.

Lot $\mathrm{n}^{\circ} 2$ (30 rats): rats received oral 2 g Doliprane $\AA / \mathrm{kg}$ body weight and treatment of $0.06 \mathrm{ml}$ of extract of Ananas comosus daily for 42 days.

Lot $\mathrm{n}^{\circ} 3$ (30 rats): rats received oral 2 g Doliprane $\AA / \mathrm{kg}$ body weight and treatment of $0.12 \mathrm{ml}$ of extract of Ananas comosus daily for 42 days.

Lot $n^{\circ} 4$ (30 rats): rats received oral 2 g Doliprane ${ }^{\circledR} / \mathrm{kg}$ body weight per day for 42 days and no treatment with Ananas comosus extract.

The animals were observed daily for their general behaviour and survival. Dead rats were immediately removed from each group and autopsied. On the $42^{\text {nd }}$ day, the survivors were sacrificed under chloroform anaesthesia. Abdominal cavity of each animal was surgically incised for a thorough examination of viscera. Kidney and liver were removed and fixed in Bouin's fixative, processed, embedded in paraffin, sectioned to a thickness of $5 \mathrm{ml}$, and stained with haematoxylin and eosin (HE) or Periodic acid Schiff (PAS) for microscopic examination.

\section{RESULTS}

Macroscopic and microscopic lesions in liver and kidney of the intoxicated rats
No clinical sign of intoxication or mortality was observed in the animals. The liver of the intoxicated rats without treatment with Ananas comosus had a yellowish colour, compared with normal liver dark red colour characteristic. The consistency of liver in intoxicated rats was friable.

The liver of rats intoxicated with Doliprane ${ }^{\circledR}$ and treated with the extract of Ananas comosus showed no difference in morphological terms compared to that of rats of group $\mathrm{n}^{\circ}$ 1. About kidney, no particular morphological characteristic was observed in rats of the different groups, but the kidney was more friable in group $\mathrm{n}^{\circ} 4$. In photonic microscopy, the liver structure in rats showed polyhedral cells (hepatocytes) with a nucleus round and a nucleolus clearly visible. The hepatocytes formed spans well arranged around the centrobular vein.

The hepatocytes store significant quantities of pink coloured glycogen. The cytoplasm of hepatocytes showed a basophile structure (Figures 1a and 1b). The effect of histological Doliprane ${ }^{\circledR}$ results in changes characterized by the appearance of cellular necrosis and centrolobular congestion with periportal congestion (around the space vessels surrounding the lobule liver door), necrotic outbreaks, cytoplasmic vacuoles, and the dislocation of liver cells with loss of cellular junctions.

Thus, hepatocytes were bigger and the arrangement of cell spans around the centrolobular vein was more visible (Figure $2)$. All these disruptions were improved in the livers of Wistar rats of group $n^{\circ} 2$ and $n^{\circ} 3$ (Figures 3 and 4). As seen in the kidneys' structures of animals of group $n^{\circ} 1$, the renal glomerulus with capillary flocculus, the glomerular board, the vascular pole and the excretory channels were normal. These structures were modified in the kidneys of rats of group $n^{\circ} 2, n^{\circ} 3$ and $n^{\circ} 4$. Despite the use of the extract of the Ananas comosus, the destruction of kidneys' structures was not reversible in rats of groups $n^{\circ} 2$ and $n^{\circ} 3$ (Figures 5, 6 and 7).

\section{DISCUSSION}

The liver is the principal organ of detoxication because it contains most of 


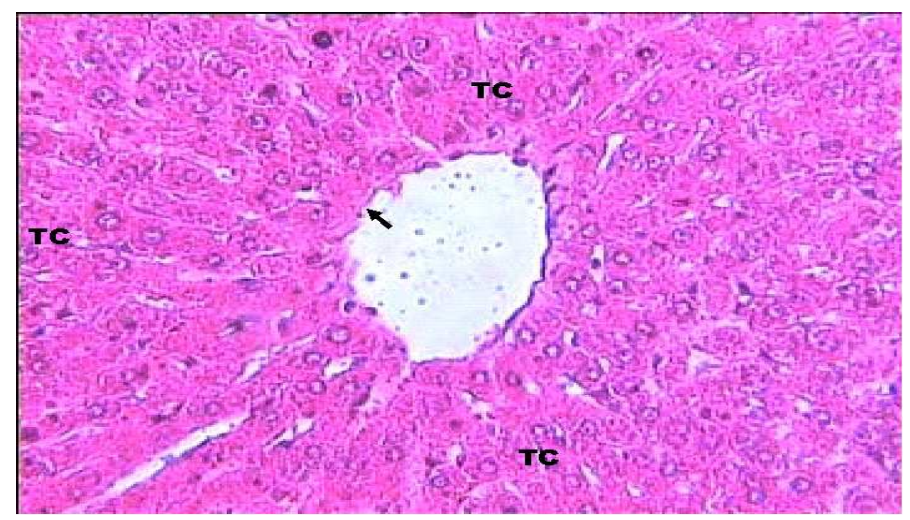

Figure 1a: Normal liver lobule (HE X 20): centrolobular vein (Arrow) around which the liver cells are organized in cellular spans (TC) arranged such as radial.

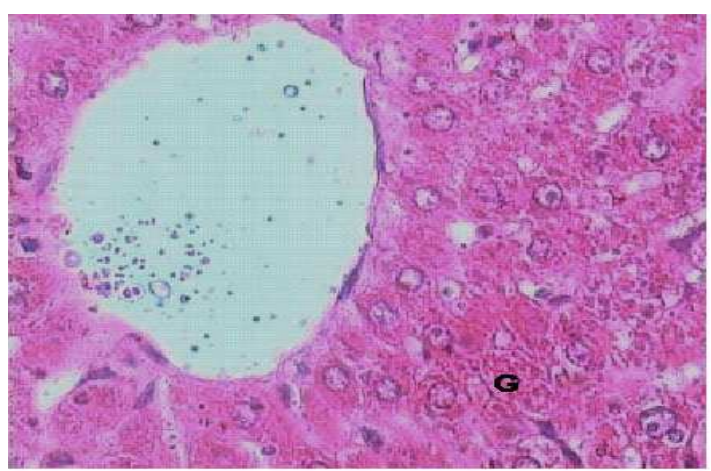

A : HE

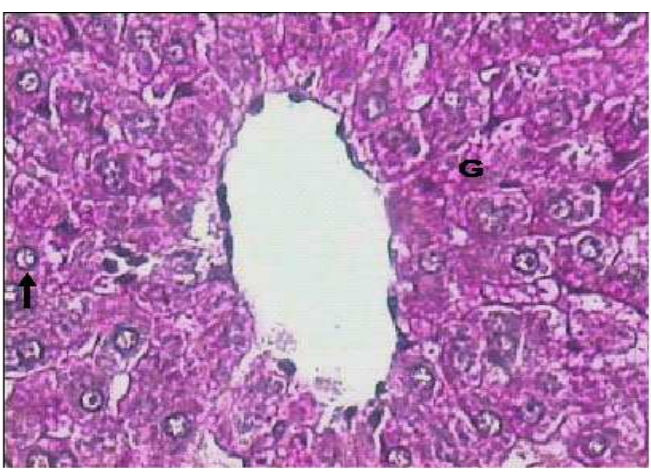

B : PAS

Figure 1b: Normal liver (magnification X 40): In the cytoplasm, refringent clusters with HE (A) and coloured red to purple with PAS (B) correspond to the glycogen $(\mathrm{G})$. The kernels are clearly visible (Arrow) with a well designed nucleolus.
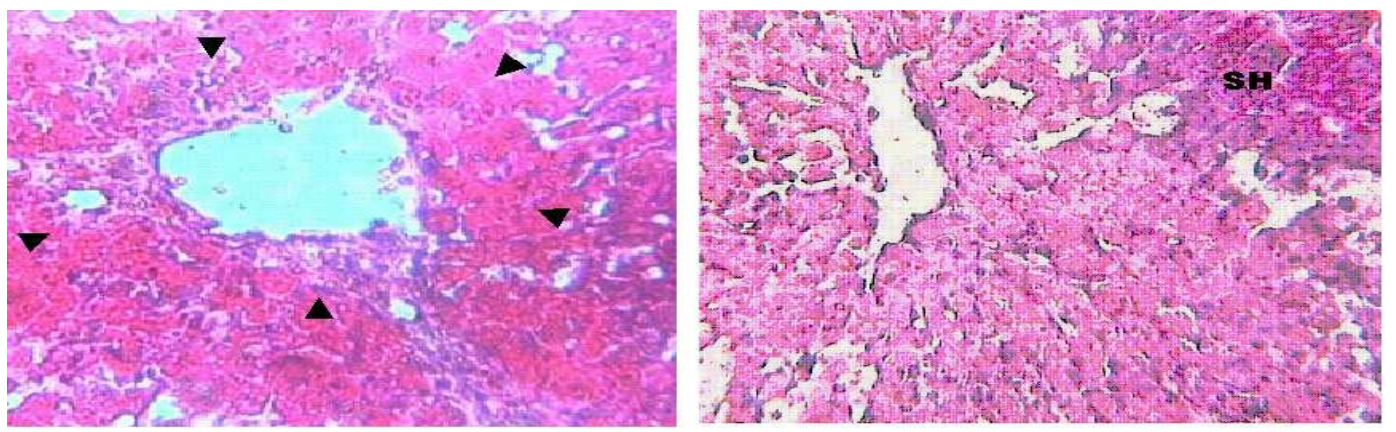

Figure 2: Animals' liver intoxicated with paracetamol but untreated (magnification $X$ 20): necrosis of hepatocyte predominant in the centrolobular region marked by a homogenization of the structure of the cytoplasm that becomes very eosinophilic, disappearance of the nucleus and limits cell (Arrows). At distance of the centrolobular vein, the structure of hepatocytes still relatively preserved (SH). 


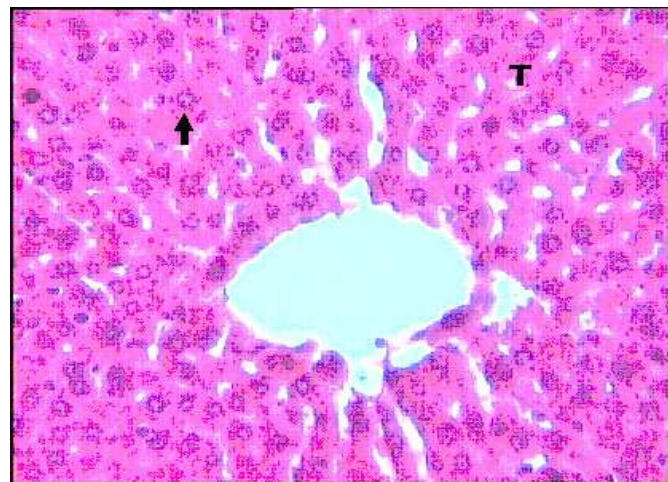

A: HE

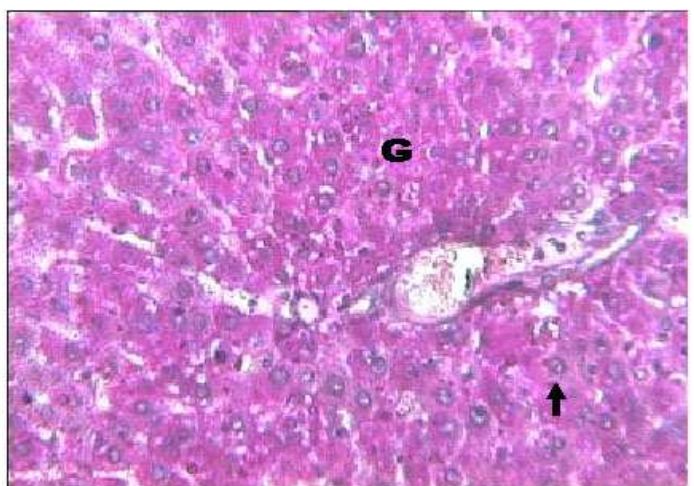

B: PAS

Figure 3: Liver of intoxicated animals with paracetamol and treated with $0.12 \mathrm{ml}$ of Ananas comosus' extract (magnification X 20). Liver architecture is almost normal; hepatocytes organized spans (T) show cytoplasm containing glycogen $(\mathrm{G})$ and a visible nucleus (Arrow).

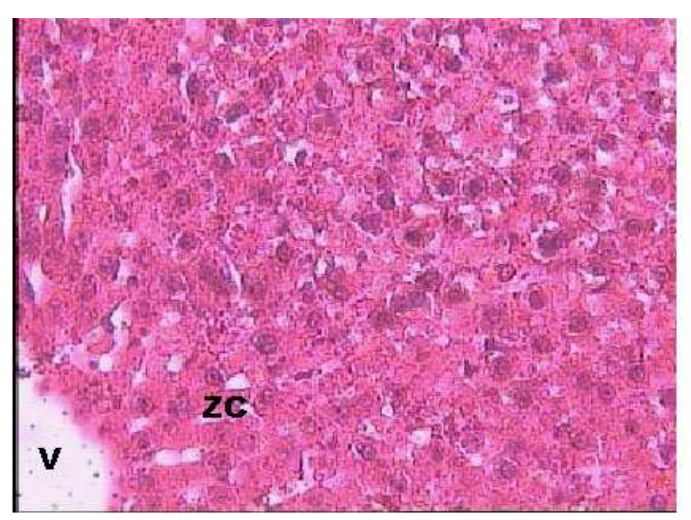

A: HE

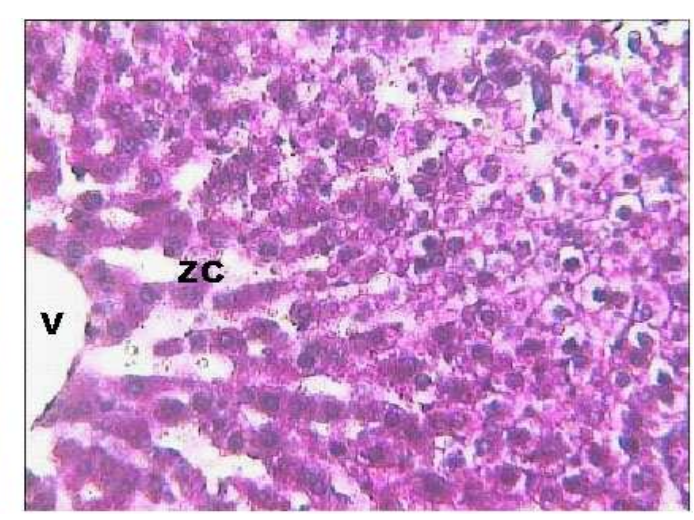

B: PAS

Figure 4: Liver of intoxicated animals with paracetamol and treated with $0.06 \mathrm{ml}$ of Ananas comosus' extract (magnification X 20). There is a reparation beginning in the centrolobular region (ZC). The hepatocytes remain small, but their organization is already visible ( $\mathrm{V}=$ centrolobular vein).

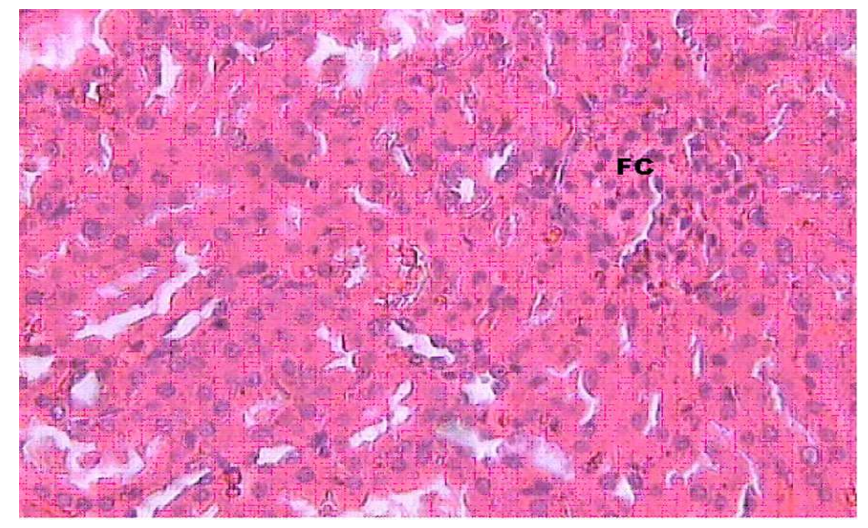

Figure 5: Renal cortex from rat intoxicated with paracetamol (HE X 20). Thickening of the interstitium, which compresses the flocculus capillary with disappearance of the glomerular room (FC). 


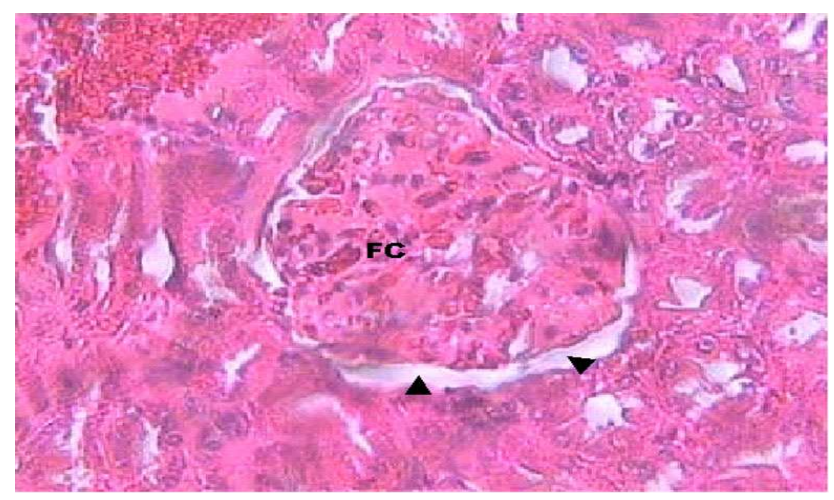

Figure 6: Renal cortex of rat intoxicated with paracetamol and treated with $0.06 \mathrm{ml}$ Ananas comosus' extract (HE X 20): thickening of the interstitium with compression of flocculus capillary (FC) and closed glomerular room (Arrows).

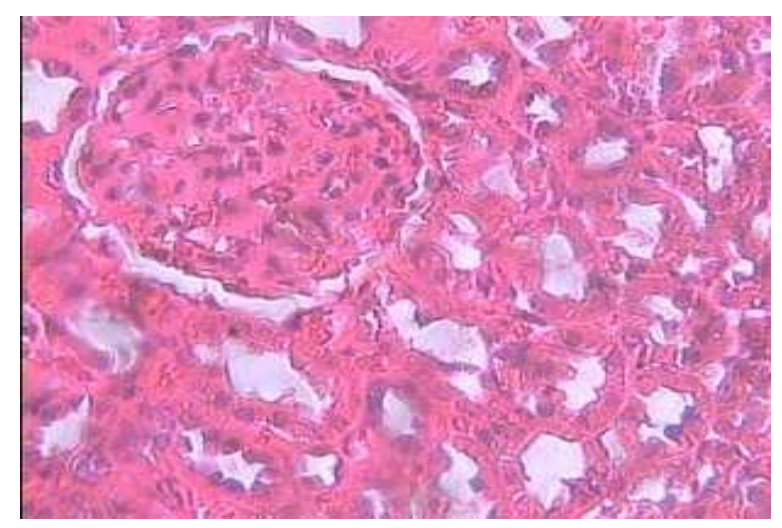

Figure 7: Renal cortex of rat intoxicated with paracetamol and treated with $0.12 \mathrm{ml}$ of Ananas comosus' extract (HE X 20): identical situation as figure 6.

metabolic enzymes, for example concentrations of glutathione and the cytochrome P-450 are very increased (Boukerche et al., 2007). That has been confirmed by high levels of transaminases and alkaline phostases during a previous liver poisoning rats by Doliprane® (Dougnon et al., 2007). The disruption of the liver enzyme system was already indirectly underscored by the increase in liver weight of rats treated with nitrate and nitrite (Batina, 1990). A lesion in the hepatocytes induces a low level of gluthation observed in the rats of group 4 what is corrected with Ananas comosus in the groups 2 and 3 in this study (data not related in the present document). In addition, the kidney plays a key role in the excretion of waste metabolism and in maintaining fluid and electrolyte balance of the body (Mc Geown, 2003).

The increase in kidney vascular body weight was more obvious than the liver. This increase in the weight of kidneys may be explained by tissue damage, as demonstrated by histological studies. Such results have been obtained by Til (1995) in rats intoxicated with grain contaminated with nitrites. Doliprane ${ }^{\circledR}$ is an analgesic which is able to induce nephropathy. This is usually accompanied by a largely irreversible kidney failure when it is used at a high dose for a long time (Cullen, 2005). The data obtained in this study showed the failure of Ananas comosus to reduce kidneys lesions due to paracetamol's toxicity in albinos Wistar rats. 


\section{Conclusion}

concluded that:

In the light of the foregoing, it can be

- Paracetamol used for liver and kidney toxicity study induced alterations in the liver and kidney of Wistar rats.

- Liver damage caused by Doliprane ${ }^{\circledR}$ was corrected in animals treated with the extract of Ananas comosus.

- The extract of Ananas comosus was not effective for the recovery of kidney impairment associated with Doliprane $\AA$ intoxication in these animals.

\section{REFERENCES}

Antoine DJ, Williams DP, Park BK. 2008. Understanding the role of reactive metabolites in drug-induced hepatotoxicity: state of the science. Expert Opin Drug Metab. Toxicol., 4(11): 1415-1427.

Batina P.1990. In vitro kinetics of the oxidative reactivity of nitrate and nitrite in the rat erythrocytess. Food Addit Contam., 1(4): 145-149.

Boukerche S, Aouacheri W, Saka S. 2007. Les effets toxiques des nitrates: étude biologique chez l'homme et chez l'animal. Ann. Biol Clin., 65(4): 385-391.

Cullen JM. 2005. Mechanistic classification of kidney injury. Toxicol Pathol., 33: 6-8.
Dougnon TJ, Kpodékon TM, Adjagba M. 2007. Biochemical effectiveness in liver detoxication of fresh pineappple (Ananas comosus) with the Wistar rats, previously intoxicated by Doliprane ${ }^{\circledR}$. Journal of Cell and Animal Biology, 2(2): 31-35.

Ichai P, Samuel D. 2008. Etiology and prognosis of fulminant hepatitis in adults. Liver Transpl., 14(2): 67-79.

Lenoir C, Lemoine A, Hillon P. 2003. Incidence of drug-induced hepatic injuries: a French population-based study. Hepatol., 36: 451-455.

Liu GT. 2009. Bicycler: a novel drug for treating chronic viral hepatitis $\mathrm{B}$ and $\mathrm{C}$. Med. chem., 5(1): 29-43.

Lorke D. 1983. A new approach to practical acute toxicity testing. Archives of Toxicology., 54(2): 275-287.

McGeown JG. 2003. Physiologie : l'Essentiel ( $7^{\text {ème }}$ édn). Maloine: Paris; 226-229.

Parks JH, Lee HH, Ju SK, Lee MK, Kim KL. 2001. Expanded-bed chromatography in primary protein purification. $J$. Chromatogr., 22(1); 60-69.

Sofowora A. 1996. Plantes Médicinales et Medicine Traditionnelle d'Afrique (1 ${ }^{\text {ère }}$ édn). Kharthala: Paris ; 20.

Til HP. 1995. Short-term oral toxicity in rats with nitrite addedb to a cereal basal diet. Interim Repp TNO Neth., 85(2): 288-294. 